\title{
A IMPORTÂNCIA DA PRESERVAÇÃO DA PAISAGEM HISTÓRICA E AMBIENTAL NA CIDADE DE PIRENÓPOLIS (GO)
}

\author{
Douglas Parreira Santos ${ }^{1}$
}

\author{
Manoel Rodrigues Chaves ${ }^{2}$
}

\begin{abstract}
RESUMO
O presente trabalho propõe uma discussão científica sobre a preservação do patrimônio histórico e ambiental com ênfase no Cerrado, na cidade de Pirenópolis(GO). O turismo brasileiro é conhecido mundialmente, principalmente por sua diversidade nas opções de lazer. Apesar da grande maioria dos turistas optarem pelo litoral do país, vem crescendo consideravelmente a busca pelas cidades do interior, seja pela fuga dos grandes centros, pelas paisagens exuberantes que as mesmas propiciam, tranquilidade nas férias e esportes radicais. A cidade de Pirenópolis(GO) é uma dessas cidades que movimentam sua economia no turismo. Com apoio da prefeitura e de órgãos públicos estaduais e federais, a pequena cidade do interior goiano consegue não só contar, mas também exibir suas preciosidades históricas e ambientais. Será discutido posteriormente a importância de preservar os resquícios do Cerrado brasileiro, bioma que a cada dia é desmatado, principalmente para abertura de novas áreas de pastagens e para monoculturas do agronegócio. Para fundamentar essa discussão o texto se baseou na teoria de Norman Myers, que aponta os biomas mundiais (pontos quentes) que estão em situação crítica, por conta das atividades antrópicas de cunho desenvolvimentista e econômico, e não são amparados em um planejamento ambiental adequado.
\end{abstract}

PALAVRAS-CHAVE: Patrimônio Histórico, Paisagem, Cerrado.

\footnotetext{
${ }^{1}$ Mestrando na Universidade Federal de Goiás (UFG). E-mail: douglas_santos88@yahoo.com.br

${ }^{2}$ Prof. Dr. em Geografia. Professor na Universidade Federal de Goiás (UFG). E-mail: manoel_chaves@ufg.br
} 


\title{
THE IMPORTANCE OF PRESERVATION OF HISTORIC LANDSCAPE AND ENVIRONMENT IN THE CITY OF PIRENÓPOLIS (GO)
}

\begin{abstract}
The present work proposes a scientific discussion about the preservation of historical and environmental patrimony emphasizing the Cerrado, in the city of Pirenópolis(GO). The Brazilian tourism is known worldwide, especially for his several leisure options. Although the vast majority of tourists choose at coast of the country is growing considerably the demand for inner cities or by to escape of major centers, the lush landscapes same as it provide, the vacation peace and extreme sports. The city of Pirenópolis(GO) is the one of these cities that move your economics by the tourism. Whit support from city hall and state and federal government agencies, the little inner city of Goiás cannot count only, but also show your historical and environmental preciousness. Will be discussed later the importance of preserving remnants of the Brazilian Cerrado, a biome that every day is deforestation, especially for opening new areas of pastures and monocultures the agribusiness. To substantiate this discussion the next was based on the theory of Norman Myers, that is points for biomes world (Hot Spots)that are in critical situation, because of the developmental nature anthropogenic activities and economic and are not supported by an environmental planning appropriate.
\end{abstract}

Key-Worlds: Preservation of Historical, Landscape, Cerrado

\section{LA IMPORTANCIA DE LA PRESERVACIÓN DE PAISAJE HISTÓRICO Y MEDIO AMBIENTE EN LA CIUDAD DEL Pirenópolis (GO)}

\begin{abstract}
RESUMEN
El presente trabajo propone uma discusión científica sobre la preservación histórico y ambiental conénfasis em el Cerrado, em la ciudade de Pirenópolis(GO). El turismo brasileño es conocido mundialmente, principalmente por su diversidade em las opciones de ócio. Apesar de la gran mayoria de los turistas opten por el litoral del país, viene creciendo considerablemente la búsqueda por las ciudades del interior, sea por la fuga de los grandes centros por los paisajes exuberantes que las mismas propcian, tranuilidad em las vacaciones y deportes radicales. La ciudad de Pirenópolis(GO) es uma de essas ciudades que mueven su economia em el turismo. Com apoyo del ayuntamiento y de órganos públicos provinciales y federales, la pequena ciudad del interior goiano consegue no sólo contar, pero también exhibir sus preciosidades históricas y ambientales. Será discutido posteriormente la importância de preservar los resquícios del cerrado, bioma que cada dia es desmatado, principalmente para apertura de nuevas áreas de pastagens y para monuculturas del agronegócio. Para fundamentar esa discusión el texto se basó em la teoria de Norman Myers, que apunta los biomas mundiales (puntos calientes) que están em situación crítica, por cuenta de las atividades humanas de naturaliza desenvolvimentista y económico, y no son amparados em uma planificácion ambiental adecuado.
\end{abstract}

PALABRAS-CLAVE: Patrimônio Histórico, Paisaje, Cerrado. 


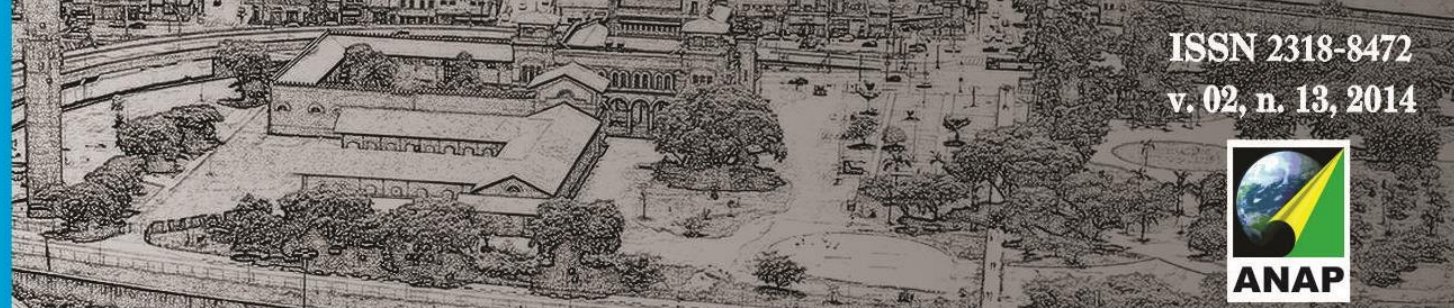

Revista Nacional de

Gerenciamento de Cidades

FIGURA 1. LOCALIZAÇÃO DA CIDADE DE PIRENÓPOLIS(GO)

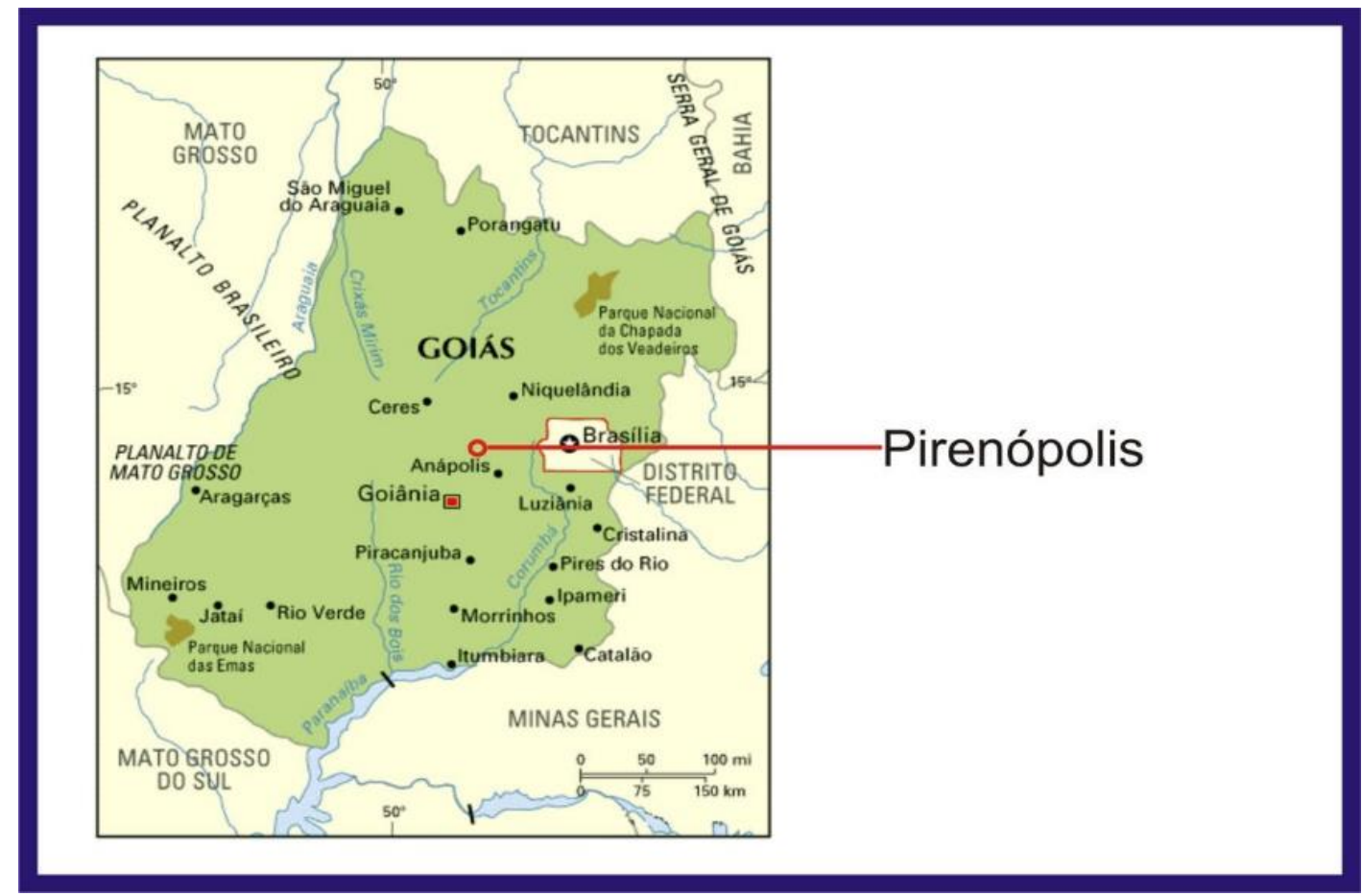

Fonte: Disponível em <http://www.apoema.com.br/pirenopolis_mapa.jpg> Acesso em 20.09.2014

Pirenópolis(GO), é um atrativo turístico pelo seu clima, fauna e flora exuberantes, provindos do quase extinto Cerrado brasileiro. A cidade visa a importância da preservação da paisagem histórica e ambiental, o que favorece o turismo no local. Visitar a cidade é fazer uma viagem no passado do estado de Goiás, seja pela cultura preservada ou por seus casarões, ruas, igrejas e arquitetura colonial da época da ocupação do território goiano.

\section{A PAISAGEM HISTÓRICA COMO MARCO NA CIDADE}

Em 1989 a cidade foi tombada como conjunto arquitetônico, urbanístico, paisagístico e histórico pelo IPHAN (Instituto do Patrimônio Histórico e Artístico 



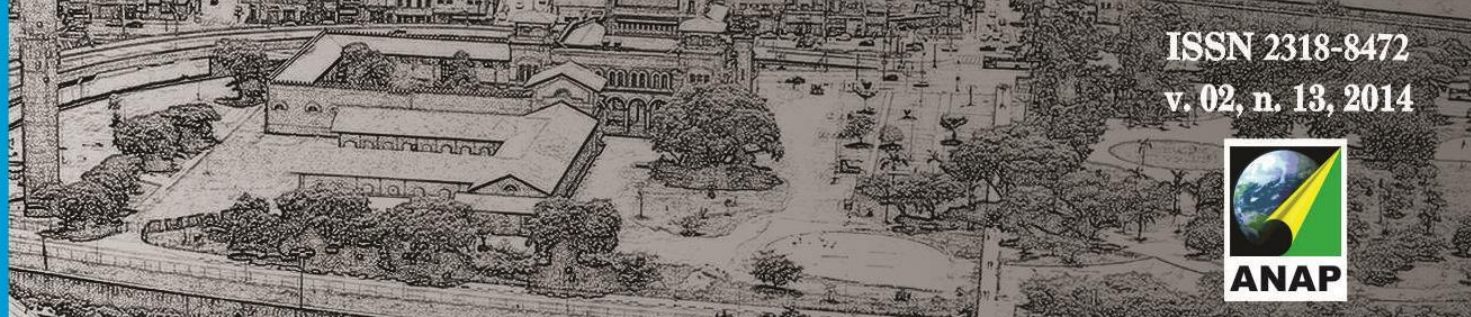

Revista Nacional de

Gerenciamento de Cidades

FIGURA 4. IGREJA NOSSA SENHORA DO ROSÁRIO PÓS RESTAURAÇÃO

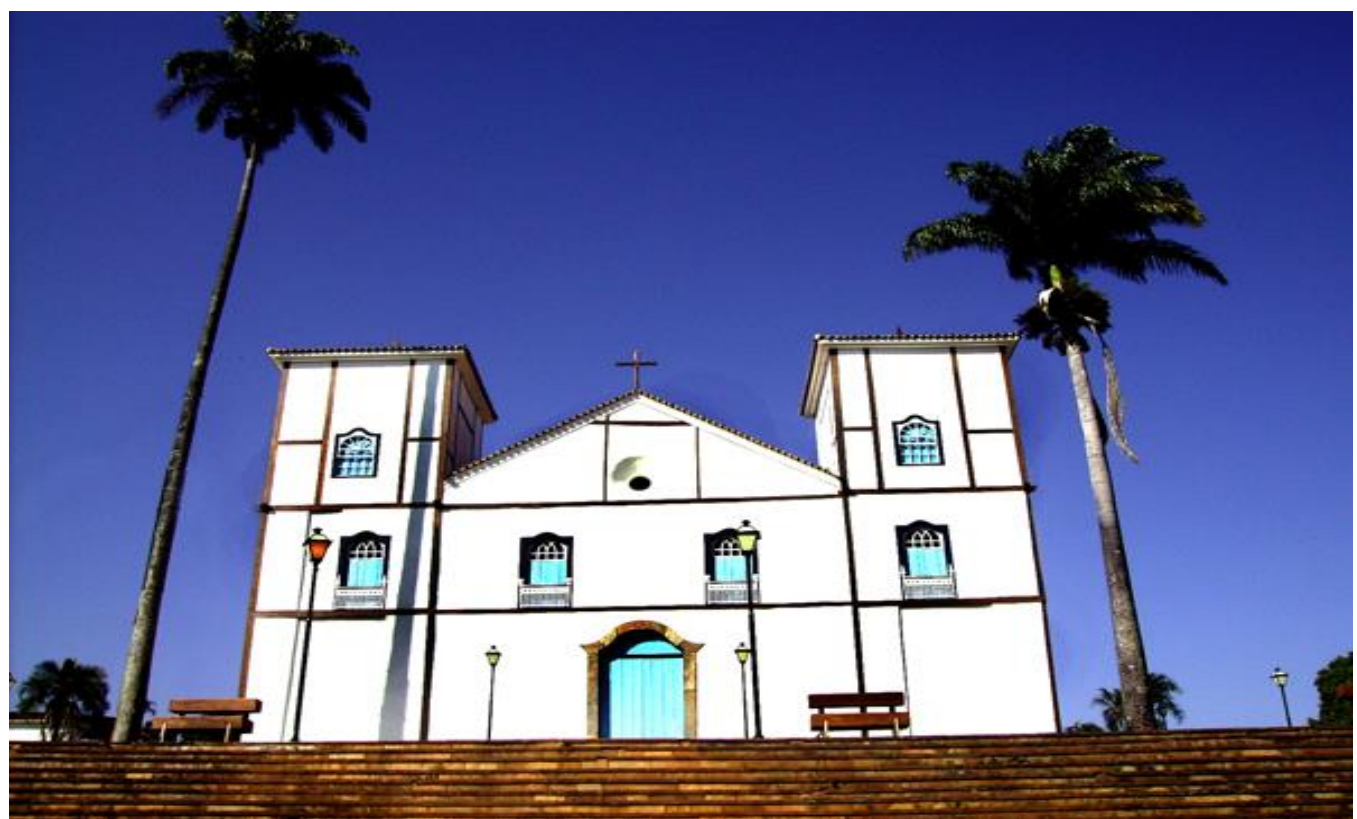

Fonte: Disponível em <http://www.pirenopolis.go.gov.br/uploads/2011/06/lgreja-Matriz-de-Nossa-

Senhora-do-Rosario-Marcos-Vieira.jpg > Acesso em 20.09.2014

Apesar de ter passado por um processo minucioso de restauração, a Igreja perdeu grande traços históricos que possuía desde que foi construída. Em termos históricos, de acordo com Cardoso e Mauad (1997, p. 406) "é indiscutível a importância da fotografia como marca cultural de uma época, não só pelo passado ao qual nos remete, mas também, e principalmente, pelo passado que ela traz à tona. Um passado que revela, através do olhar fotográfico, um tempo e um espaço que fazem sentido", continuam afirmando que a fotografia tem "um sentido individual que envolve a escolha efetivamente realizada; e outro, coletivo, que remete o sujeito à sua época" (p. 406).

Os traços históricos que foram destruídos pelas chamas, não foram apagados da mente da população de Pirenópolis(GO), a paisagem mostrada para os turistas que visitam a cidade, é diferente da paisagem interpretada pela população local. $O$ passado, seja mostrado em fotos, vídeos ou em simples lembranças em nossas 


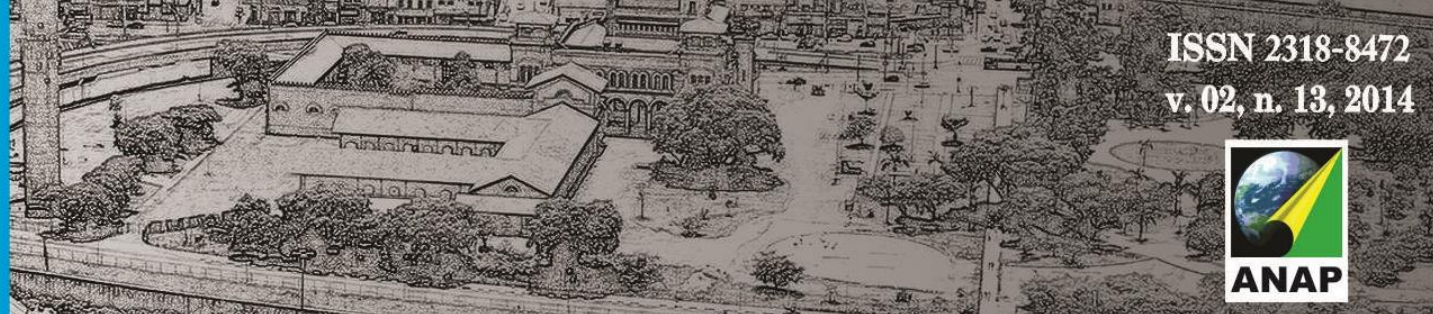

Revista Nacional de

Gerenciamento de Cidades

mentes, são diferentes tipos de interpretações dos vários elementos que integram a paisagem. Sobre a questão das representações da paisagem:

Por não possuir uma existência em si, mas sim ser a essência em si do espaço que representa, podemos representa-la de várias formas. Essa representação evoluiu na história da civilização desde as pinturas rupestres, passando pelas aquarelas, gravuras, fotografias, etc. (SANTOS, 2006, p. 140).

Baseado na definição clássica de paisagem de Milton Santos (1988, p. 61):

[...] tudo aquilo que nós vemos, o que nossa visão alcança, é a paisagem. Esta pode ser definida como o domínio do visível, aquilo que a vista alcança. Não é apenas formada de volumes, mas também de cores, movimentos, atores, sons, etc. (SANTOS, 1988. p. 61)

A paisagem na visão miltoniana é vista como um dado humano. Não é algo palpável e homogêneo. A paisagem é uma variável, um bem mutável, criado através da sensibilidade e das experiências do observador. Pode se observar a mesma paisagem de um local exato, no mesmo dia e horário, os elementos que integram a mesma, baseado na vivência de quem observa, será o fator que determinará a diferença entre as paisagens observadas.

\section{MEIO AMBIENTE: PRESERVANDO OS RESQuícIOS DO CERRADO BRASILEIRO}

A cidade de Pirenópolis(GO), também se preocupa com a preservação da paisagem ambiental. A cidade é cercada por morros e tem uma visão privilegiada dos mesmos. Situada aos pés da Serra dos Pireneus, o município goiano possui oito UC's (Unidades de Preservação). Parques: Parque Estadual da Serra dos Pireneus, Monumento Natural (Monumento Natural Cidade de Pedra), Área de Preservação Ambiental (APA dos Pireneus) e cinco RPPN's (Reserva Particular do Patrimônio Natural: Fazenda Arruda, Reserva Ecológica Vargem Grande, Fazenda Vagafogo, Santuário Flor das Águas e Santuário Gabriel. 


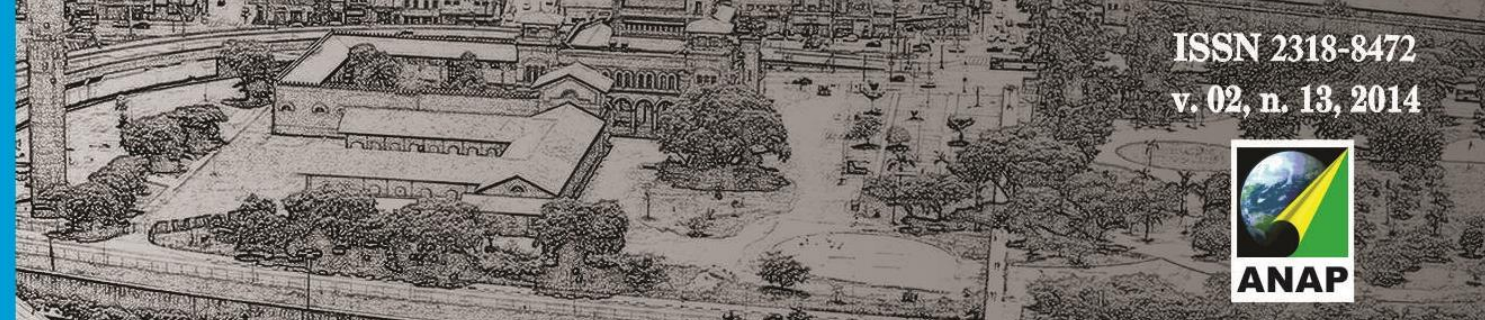

Revista Nacional de

Gerenciamento de Cidades

Em 2005 Myers, trouxe um atualização do seu conceito. As áreas críticas aumentaram de oito para trinta e quatro, isso mostra que apesar do alerta anterior as ações antrópicas contra alguns biomas continuaram a serem realizadas. Nessa nova etapa de estruturação do conceito, Myers incluiu dois subitens para que uma área seja considerada um Hot Spot: a) Deve conter, pelo menos, 1500 espécies de plantas vasculares $(0,5 \%$ do total do planeta) como endêmicas; b) Deve ter perdido pelo menos $70 \%$ do seu habitat original. Com essa nova denominação o Cerrado brasileiro entrou na lista de Myers como área de preservação crítica.

\section{FIGURA 6. HOT SPOTS ATUAIS}

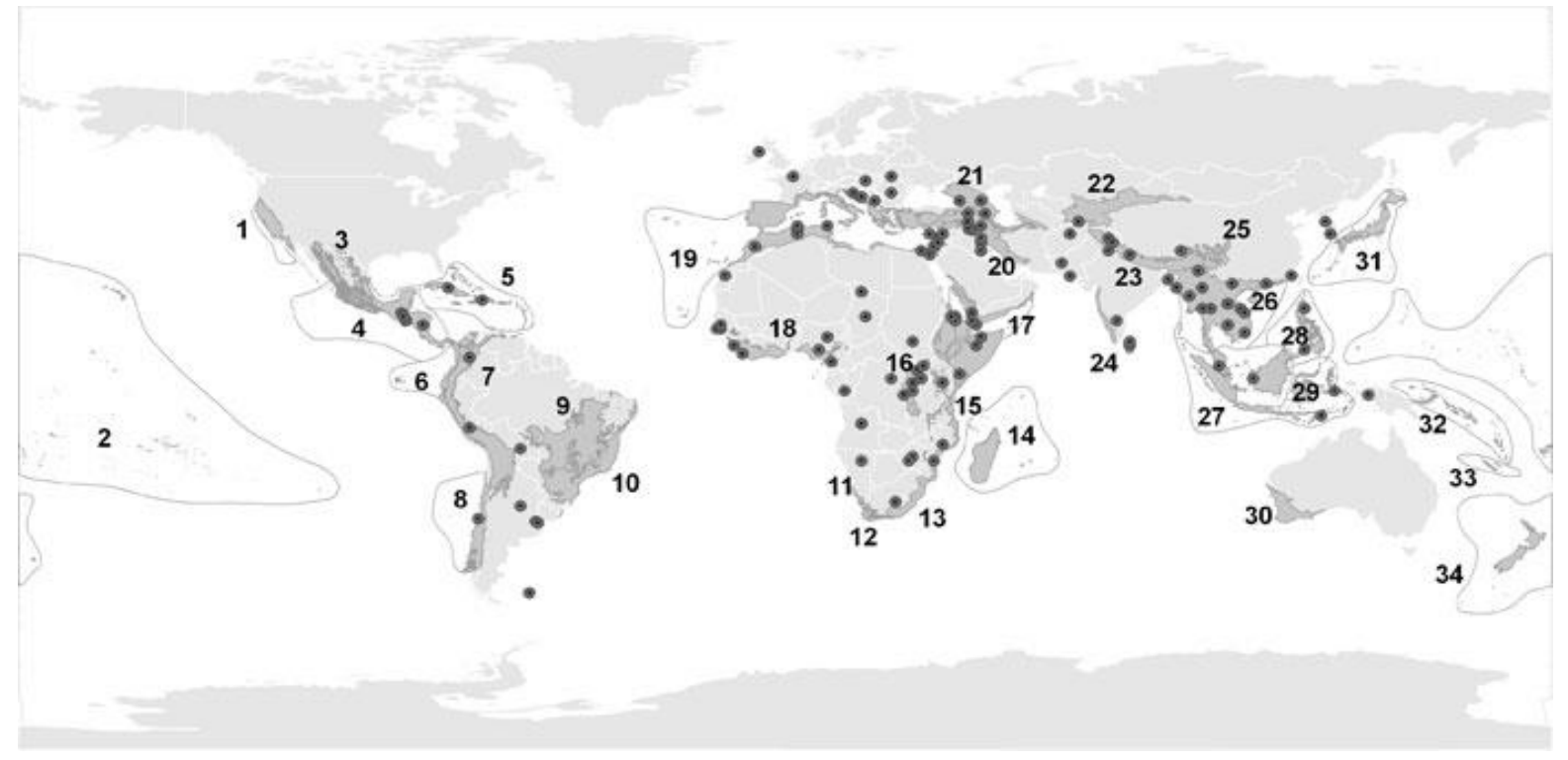

Fonte: Disponível em

<http://sp10.conservation.org/SiteCollectionlmages/maps/700_hotspots_conflicts_map.jpg> 18.09.2014

Outro fator que impulsiona a extinção do Cerrado brasileiro é a urbanização turística. Segundo Cruz (2001) 


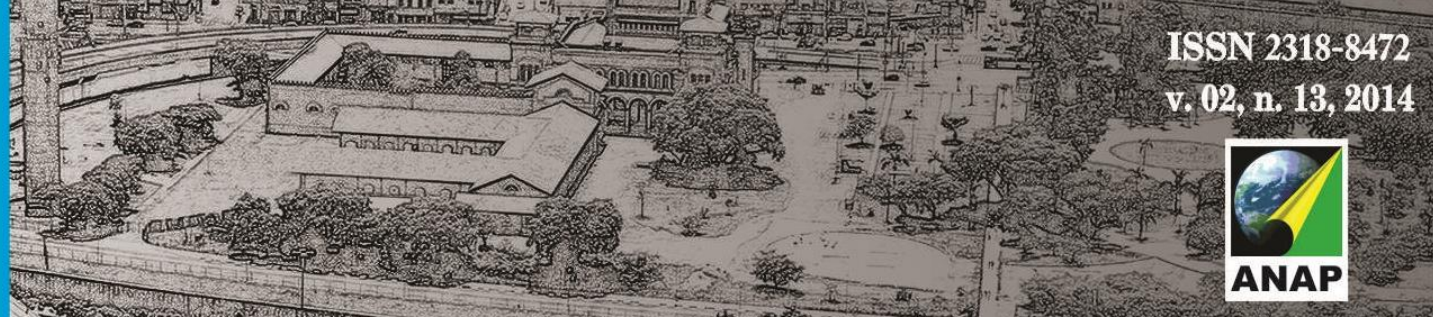

Revista Nacional de

Gerenciamento de Cidades

então, induzir o desenvolvimento do turismo, por meio de políticas e do planejamento, caso essa incorporação espontânea não ocorra, direcionando os equipamentos urbanos já construídos e aqueles a construir, em função de uma urbanização para o turismo. (CRUZ, 2001, p.25)

Se não há uma rigorosa supervisão e controle do desenvolvimento do turismo por parte dos governos, deixa-se as principais decisões a cargo das empresas que só visualizam retirar proveito (lucro) naquilo que estão investindo segundo seus próprios interesses, sem pensar nas condições de vida da comunidade local, do meio ambiente, do patrimônio histórico-cultural. Sobre este assunto é interessante destacar a questão da urbanização turística que está se processando em diversas partes do Brasil. É um movimento que expressa a força que é outorgada aos agentes promotores do turismo, por grandes grupos empresariais brasileiros e estrangeiros. A urbanização turística coloca as cidades no mercado de paisagens naturais e artificiais. Nas palavras de Luchiari (1998, p.17), "algumas cidades chegam a redefinir toda sua vida econômica em função do desenvolvimento turístico, reorganizando-se para produzir paisagens atrativas para o consumo e para o lazer".

Essa remodelação das cidades turísticas afeta a sua própria origem. A cidade de Pirenópolis(GO), tem sido alvo assíduo de grandes empresas, com intuito de construção de hotéis e parques de lazer. A prefeitura criou leis que impossibilitem esse tipo de ação, para que a origem da cultura histórica da cidade seja preservada e continue sendo o atrativo turístico necessário para impulsionar a economia local. Isso deriva de um planejamento necessário e importante por parte da gestão pública da cidade, que segundo Yázagi (1999):

Ao se produzir um espaço para ser consumido como lugar turístico, se não houver um planejamento enfocado para o turismo sustentável, destrói-se, dessa forma, as próprias condições que deram origem a este produto, essa mercadoria, que tanto é parte da indústria como do setor de serviços. (YÁZIGI 1999, p.55) 


\section{REFERÊNCIAS}

CARDOSO, C. F.; MAUAD, A. M. História e imagem: os exemplos da fotografia e do cinema. In: CARDOSO, Ciro Flamarion, VAINFAS, Ronaldo (Orgs.). Domínios da história: ensaios de teoria e metodologia. 5a ed. Rio de Janeiro: Campus, 1997. p. 401-417.

\section{Consulta de Monumentos Tombados: Disponível em: http://portal.iphan.gov.br/portal/montarPaginaSecao.do?id=15145\&retorno=paginalphan. Acessado em 20 de Setembro de 2014 ás 10:30.}

CRUZ, R.C.A. Introdução à geografia do turismo. São Paulo: Roca, 2001.

Hot Spots Mundiais. Disponível em http://www.conservation.org/Pages/default.aspx. Acessado em 18 de Setembro de 2014 ás 11:15.

Igreja Nossa senhora do Rosário Pirenópolis(GO): Disponível em http://www.pirenopolis.tur.br/turismo/atrativos/centro-historico/igreja-matriz. Acessado em 20 de Setembro de 2014 ás 11:00.

Informações sobre a cidade de Pirenópolis(GO): Disponível em: http://www.pirenopolis.com.br/index.jsp. Acessado em 19 de Setembro de 2014 ás 08:50.

LUCHIARI, M.T.D.P. Urbanização turística: um novo nexo entre o lugar e o mundo. LIMA, L.C. (org.) Da cidade ao campo: a diversidade do saber fazer turístico. Fortaleza: UECE, 1998, pp.15-29.

MURTA, Stela M.; ALBANO, Celina. Interpretação, preservação e turismo: uma introdução. In: MURTA, Stela M.; ALBANO, Celina (org). Interpretar o patrimônio: um exercício do olhar. Belo Horizonte: UFMG, 2005. p. 9-12.

MURTA, Stela Maris; GOODEY, Brian. Interpretação do patrimônio para visitantes: um quadro conceitual. In: MURTA, Stela Maris; ALBANO, Celina (Org.). Interpretar o patrimônio: um exercício do olhar. Belo Horizonte: Editora UFMG, 2005. p. 13-46.

MYERS, N., R.A. Mittermeier, C.G. Mittermeier, G.A.B. Fonseca \& J. Kent. 2000. Biodiversity hotspots for conservation priorities. Nature 403: 853-858.

MYERS, N. (1988). Threatened Biotas: "Hot Spots" in tropical forests The Enviromentalist, 187208.

SANTOS, Milton. Metamorfoses do espaço habitado. São Paulo: HUCITEC, 1988. p. 61.

YAZIGI, E. Civilização urbana: planejamento e turismo. São Paulo: Contexto, 2003. Organização Mundial do Turismo - www.wto.org.br 